Viviani Rios Kwecko Artes do Instituto de Educação Ciências Clencias

Rio Grande do

SUI-IFRS outoranda en

Educação em Ciências- FURG

Coordena projetos de pesquisa na áre Arte e Educação

Profissiona Educação UFPel.

Dandara Bueno Espíndola Alun do Curso de Fisioterapia/ UNIRITTER Técnica en Automaçâo Industria

Bailarina formad pela Escola de Belas Artes Heito de Lemo Professora de Ballet Clássico na Academ Geração Eleita

\section{O acontecer no amanhecer: Desdobramentos de autoconhecimento através da prática do happening}

Happening at daybreak: Developing selfknowledge through happening practice.

Resumo: Este texto busca refletir sobre o lugar que se destina a Arte na formação profissional de jovens estudantes do Instituto Federal de Educação, Ciências e Tecnologia do Rio Grande do Sul - IFRS, Campus Rio Grande. A partir desse extrato narramos a concep̧̧ăo e execução de una intervençăo estética no ambiente escolar, cujo objetivo, mosmo que de forma inconsciente por parte dos alunos, foi problematizar o tecnicismo de sua formação. O happening aqui descrito fol executado em 2012 pelos alunos do curso Técnico Integrado de Automação Industrial. O relato dos alunos serve como substrato para discussão do processo de concepção da atividade levando em consideração seu cotidiano e o tempo que despendiam na instituição, criando um diálogo rer da atividade e os desdobramentos que levaram a transformação dos estudantes.

Palabras clave: cuerpo, materialización, poder, prácticas artístico-sociales, activismo.

Abstract: Abstract: This text seeks to discuss the intended place of art in relation to the professional training and education of young students at the Instituto Federal de Educação Ciência e Tecnologia Rio Grande do Sul (Federal Institute of Education, Science and Techonology) - IFRS, Rio Grande Campus. This is the starting point from which we consider the conception and execution of an aesthetic intervention in the school environment, whose objective, although unconscious on the part of the students, was to problematize the technical complexity of their education. The happening described was executed in 2012 by the students in the course Integrated Technician (TI) in Industrial Automation. The students reports are the basis for this discussion about the activity's conceptual process, which took into consideration the students' daily lives and the time they spent at school creating a dialogue between leisure and school environmen Also presented are the impact on the students throughout the development of the activity and how it transformed them.

Keywords: Art; education; professional; happening; creation

\section{UM COMPLEXO MOSAICO DE HISTÓRIAS..}

O Instituto Federal de Educação, Ciências e Tecnologia - IFRS nasceu de um complexo mosaico de histórias institucionais voltadas para o compromisso com a educação profissional. Parte integrante de um projeto de desenvolvimento nacional que busca consolidar-se como soberano, sustentável e inclusivo, a Educação Profissional e Tecnológica necessita ser convocada não só para atender às novas configurações do mundo do trabalho, mas, igualmente, a formar profissionais que transcendam as demandas técnicas articulando-as com a perspectiva de formação para o conhecimento reflexivo, crítico e relacional.

Nada obstante, essa nova constituição identitária não deve limitar-se à missão institucional, mas também abrir espaços para o diálogo sobre a constituição de cada disciplina que compõem o emaranhado da formação profissional. Tal necessidade é evidenciada ao percorrermos o histórico processo de composição da Arte no campus Rio Grande do IFRS. Desde sua fundação, em 1964, sob o formato de Colégio Técnico, até o momento da inserção da instituição na rede dos IFs, a nomenclatura da disciplina se mantinha como Educação Artística, porém possuía como conteúdo programático Desenho Técnico, uma linguagem gráfica derivada da Geometria Descritiva e utilizada na indústria como padrão para representações tridimensionais.

Essa visão do papel da Arte na educação brasileira retoma as influências do liberalismo de Rui Barbosa (BARBOSA, 2005) que baseava a educação de massa na "ideia da necessidade de se propagar pelo povo o ensino de desenho e de educar a nação para o trabalho industrial" (BARBOSA, 2005, p. 53)

Foi a partir do séc. XIX, com os movimentos sociais gerados pela Revolução Francesa e intimamente relacionados com os processos de divisão do trabalho induzido pela Revolução Industrial, que surgiu
[2] Coma promulgação dezembro de 2008 dezembro de 2008 38 Institutos 38 Institutos
Federais de Educação, Ciência e Tecnologia em território brasileiro. terrionio brasilero. propostas de aço do IFRS destacado IFrs destacada educação superior, básica profissional, pluricurricular e foco na educação profissionale tecnológica em modalidades 
a tendência de imaginar que o artista e o cientista trabalhavam de maneiras diferentes e, até mesmo, antagônicas entre si. Ou seja, enquanto a Arte era, em geral, repelida pela nova sociedade industrial, a Ciência era absorvida por ela. Essa histórica segregação trouxe interpretações (e resultados) negativas, a citar, por exemplo, a crença presente em muitas salas de aula e laboratórios (principalmente na formação profissional técnica e tecnológica) de que os objetivos destas duas áreas, assim como seus processos de pensamento e de construção de conhecimento, são diferentes. Em uma análise ainda pior essa visão nos diz que apenas a ciência preocupa-se com a realidade e que a função da arte é simplesmente excitar os sentidos em um tipo de busca do ornamento e do agradável para os olhos.

Desde a aprovação, em 1996, da Lei de Diretrizes e Bases da Educação Nacional - LDB (Brasil, 1996) a Arte é considerada, oficialmente, área de conhecimento, estando incluída como componente curricular obrigatório nos diferentes níveis da educação básica (Lei n 9.394/96, artigo 26, parágrafo $2^{\circ}$, Brasil, 1996). Em 1998 a organização dos Parâmetros Curriculares Nacionais - PCN (Brasil, 1999) ratificou a importância do ensino de Arte como uma linguagem com estrutura e códigos próprios ligados à cultura artística, e não apenas como uma atividade.

Para Herbert Read (2001, p. x-xii) "é apenas quando nós reconhecemos claramente a função da Arte como um modelo de conhecimento paralelo a outros modos, através dos quais o homem chega a um entendimento de sua existência, que podemos começar apreciar sua significação na história da humanidade”. Portanto, queremos chamar a atenção da importância da Arte como tema transversal, um elemento agregador que, interpenetrando outras disciplinas, é capaz de proporcionar a produção de conhecimento integrado.

Neste sentido Lanier (2008) propõem a arte-educadores o de- senvolvimento de uma abordagem que busque ir além da promoção do crescimento pessoal, da criatividade, da percepção do contexto físico, social e emocional, objetivando urgentemente estabelecer como foco para o ensino de arte o "progresso no domínio dos procedimentos estético-visuais dos alunos". Na verdade o que Lanier nos propõem é que o ensino de Arte busque um "conceito central forte" vinculado aos referenciais artísticos cuidando de enfatizar aos estudantes que devem centrar seu trabalho nos domínios dos procedimentos estético-visuais para que possamos "devolver os conceitos da Arte à Arte-educação” (LANIER, IN: Barbosa 2008, p. 45).

Um ensino que possua como foco conceitos e saberes sistematizados pelas tendências artísticas soa, para muitos educadores, como o retorno à abordagem tradicional - um grave engano. Propomos, sim, resgatar o conteúdo conceitual, a história e a filosofia da arte, mas isso não significa romper com o interesse e a espontaneidade do aluno. Acreditamos que toda expressão, mesmo a de origem espontânea, ao ser qualificada por um processo de discriminação estético-visual, conduz a movimentos de ampliação de consciência (VYGOTSKY, 2001; FREIRE, 2009) sobre os conceitos da Arte, da criação e dos processos de auto-expressão, possibilitando um controle sobre esse fazer.

Em outro dizer, quando você vê uma igreja gótica, por exemplo percebe que ela significa alguma coisa, mas como é que vai captar este significado se não conhece suas origens? Será um edifício qualquer se não souber de onde vêm suas formas e o que significam originalmente. Gombrich, em entrevista a Barbosa (2008, p. 34), destaca que ao usarmos a linguagem temos que ter consciência de que essa se desenvolveu ao longo de milênios e que cada palavra, cada conceito não foi por nós inventado, mas herdado frente a uma interação entre os seres humanos e seu contexto social. 


\section{A CRIAÇÃO DA ARTE-EDUCAÇÃO-PROFISSIONAL}

A disciplina de Artes no IFRS é atualmente oferecida aos alunos do $2^{\circ}$ ano do Ensino Médio, com idades entre 16 e 17 anos, oriundos, em sua maioria (80\%), de escolas públicas da rede de ensino do município do Rio Grande/RS. A carga horária semanal compreende 1h5omin sendo ministrados, em média, 40 encontros ao longo dos duzentos dias letivos que compõem a exigência legal do Ministério da Educação para o Ensino Básico. Os alunos estão matriculados nos cursos técnicos na modalidade integrada (formação geral somada à formação profissional, totalizando quatro anos de estudo) nas seguintes áreas: Automação Industrial; Eletrotécnica; Informática para Internet; Geoprocessamento; Mecânica Industrial e Refrigeração e Climatização.

Diante desse cenário perguntamo-nos: qual o lugar que se pode destinar à Arte na formação profissional? Por que, no processo de constituição e organização curricular da educação profissional os aspectos estéticos, historicamente, têm recebido tratamento menos cuidadoso? Quais estratégias de problematização em Arte dialogam com os princípios e os conteúdos da educação profissional? Como romper com o tecnicismo e criar um espaço de diálogo na formação da identidade profissional desse jovem? O que é Arte para o IFRS?

É do enfrentamento de incertezas que emergem as verdadeiras conquistas do espírito humano. Nesse sentido, buscamos discutir as possibilidades e desafios de organização de uma proposta curricular integrada, complementar e mutuamente reforçada através da qual o objetivo profissionalizante não teria fim em si mesmo nem se pautaria pelos interesses do mercado. Isso significa explicar como a Arte se converte em potência material no processo de produção de um ensino que integre cultura e ciência, humanismo e tecnologia, visando o desenvolvimento das potencialidades humanas.

\section{O ACONTECER NO AMANHECER}

A experiência aqui relatada surge como uma proposta integrada de educação baseada nas ideias de Davydov, 1998, (apud LIBÂNEO, 2004 página 122) unida a elementos dos mais variados campos relacionados à área de ensino e aprendizagem, como os conceitos de Zona de Desenvolvimento Proximal (VYGOTSKY, 2001); construção do conhecimento como uma obra social (FREIRE, 1983); aprendizagem conceitual da arte (BARBOSA, 2005, 2008, EISNER, 2008); percepção de si como identidade Ambiental (PERALTA 1997; PERALTA-CASTELL 2012).

Essa composição no campo da educação inicia-se quando concebemos a aula como um "evento" de aprendizagem no qual o assunto é explorado pelo mediador/professor e o grupo de alunos de um modo aberto e significante. O desenvolvimento desta aula/evento é centrado na elaboração de uma experiência estética resultante das descobertas realizadas pelos estudantes frente a um conceito (pesquisa) que desejam descobrir. Será a partir da constituição desse momento, no qual o ato de conhecer é fruto dos desejos individuais de cada aluno, que todas as subsequentes e recorrentes fases do processo metodológico serão estabelecidas (Quadro 1).

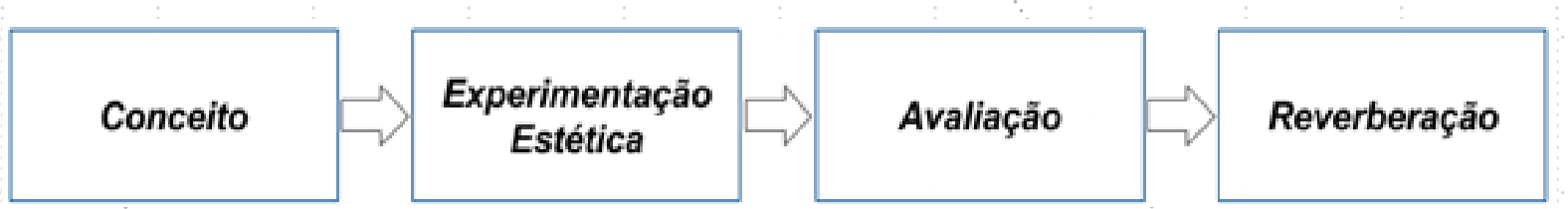

Quadro 1. Fases do processo metodológico da Arte-educação-profissional,

KWECKO 2012.)

Em uma de nossas experiências metodológicas no IFRS assumimos como problematização o conceito de Flash Mob e a relação das mobilizações dos jovens pelas redes sociais. A análise inicialmente percorreu o conhecimento de senso comum para, paulatinamente, aprofundar-se a investigação em direção à unidade germinal 
científica originária, o conceito de Happening.

Cunhada em 1959 pelo artista americano Allan Kaprow (1927 - 2006) a expressão happening refere-se a improvisações de artes visuais e cênicas realizadas em locais públicos, sem separação entre os espaços do espetáculo e da audiência. O objetivo é romper com as convenções artísticas e envolver a participação do público. Os happenings são gerados na ação e, como tal, não podem ser reproduzidos. O seu modelo primeiro são as rotinas comuns e, com isso, eles borram deliberadamente as fronteiras entre arte e vida.

Do movimento de aproximação e distanciamento entre os tempos e espaços, as dúvidas e certezas destes conceitos, surgiu a proposta de experimentação estética auto-regulada pelos jovens, que receberam apenas a consigna de (re)construir o conceito.

Em uma das propostas os alunos do Curso de Automação Industrial apresentaram como problematização/mobilização sua relação com o espaço-tempo da formação profissional. O cotidiano casa-escola dos alunos foi considerado um incitador, já que a extensa permanência estudantil no Campus vai de encontro com o lazer e conforto caseiro. Foi, então, a partir da premissa de unir esses ambientes e instigar questionamentos que a ideia de utilizar o pijama geralmente ligado ao ócio, surgiu. Para isso, determinou-se uma manhã em que a turma passasse em seus pijamas, iniciando a atividade portanto, desde a chegada dos estudantes ao IFRS (Figura 1).

Observamos que o simples fato de criar uma argumentação e percorrê-la através de um questionamento sistemático, identificando cada vertente possível de ser aventurada e desvendada, constitui-se no maior desafio. Como síntese desse processo os estudantes conceberam, em seu papel de agentes da criação, performances caracterizadas por seu aspecto de imprevisibilidade e realizadas com o objetivo de instigar a participação do público e causar fortes impressões.

A turma era composta por 32 alunos sendo que entre esses apenas dois não compareceram de pijamas, justificando interferên cias familiares. Porém a potência do ato fez-se maior, já que ambos os alunos administraram tal contratempo passando a vestir suas roupas ao avesso, integrando-se assim ao grupo de protesto. A chegada dos alunos causou estranhamento e, aos poucos, quando a turma começou a se unir os alunos foram se sentindo mais à vontade para aproveitar a experiência (Figura 2).

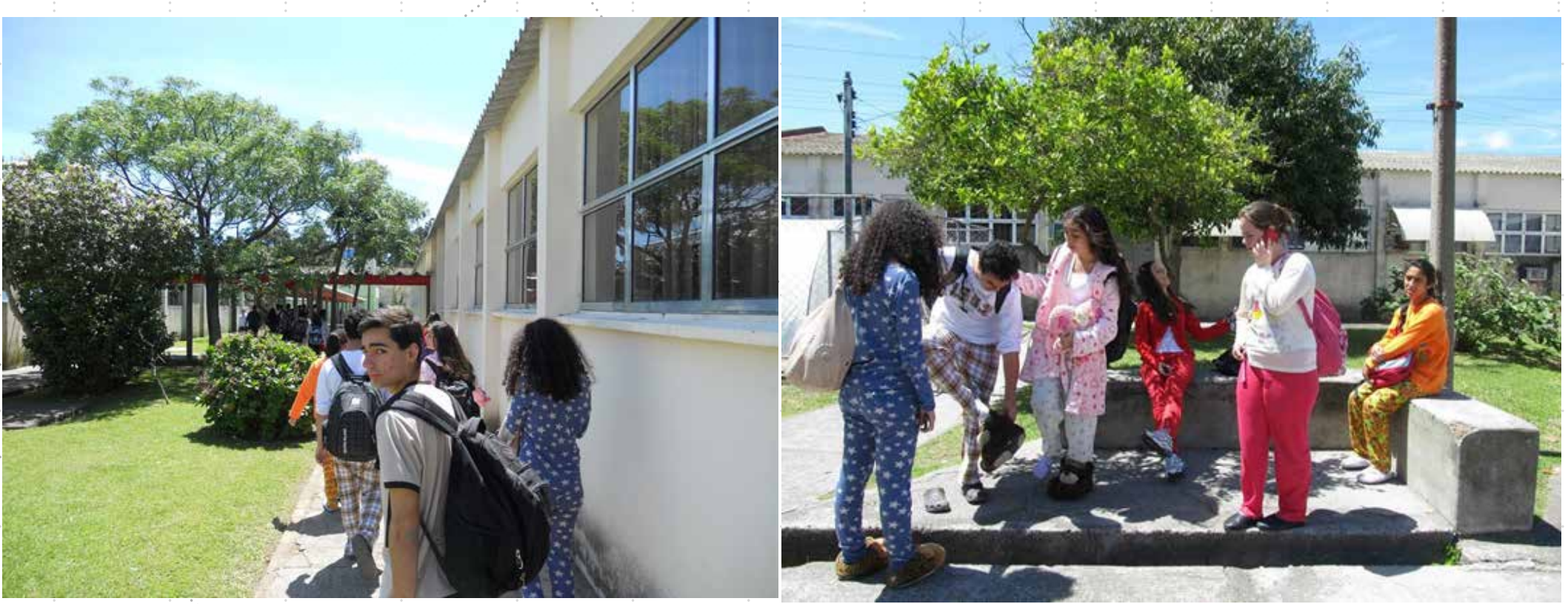

Figura 1. Registro do deslocamento do grupo pelo campus Rio Grande/IFRS, ano 2012. Fotografia de Figura 2. Alunos no pátio do Campus Rio Grande/ IFRS, ano 2012. Fotografia de Dandara Bueno Espíndola. 
A dinâmica conturbou e causou impacto na seriedade do dia-a-dia do Instituto ao desprender diversas reações e impressões do público docente e de outros alunos. Os comentários positivos eram diretos e celebrados pelo grupo, porém nos negativos eram murmúrios que circulavam entre os corredores em tom de ameaça: "isso é um atentado ao pudor, é processo para essa professora!". Realmente estávamos diante de um processo de ocupação pela Arte.

Ainda, o grupo de alunos tomou a liberdade de divertir-se com a atividade e com o deslocamento no Campus quando, inclusive, fizeram sua remontagem de uma das mais icônicas capas de álbum já feitas: Os Beatles em Abbey Road, (Figura 3).

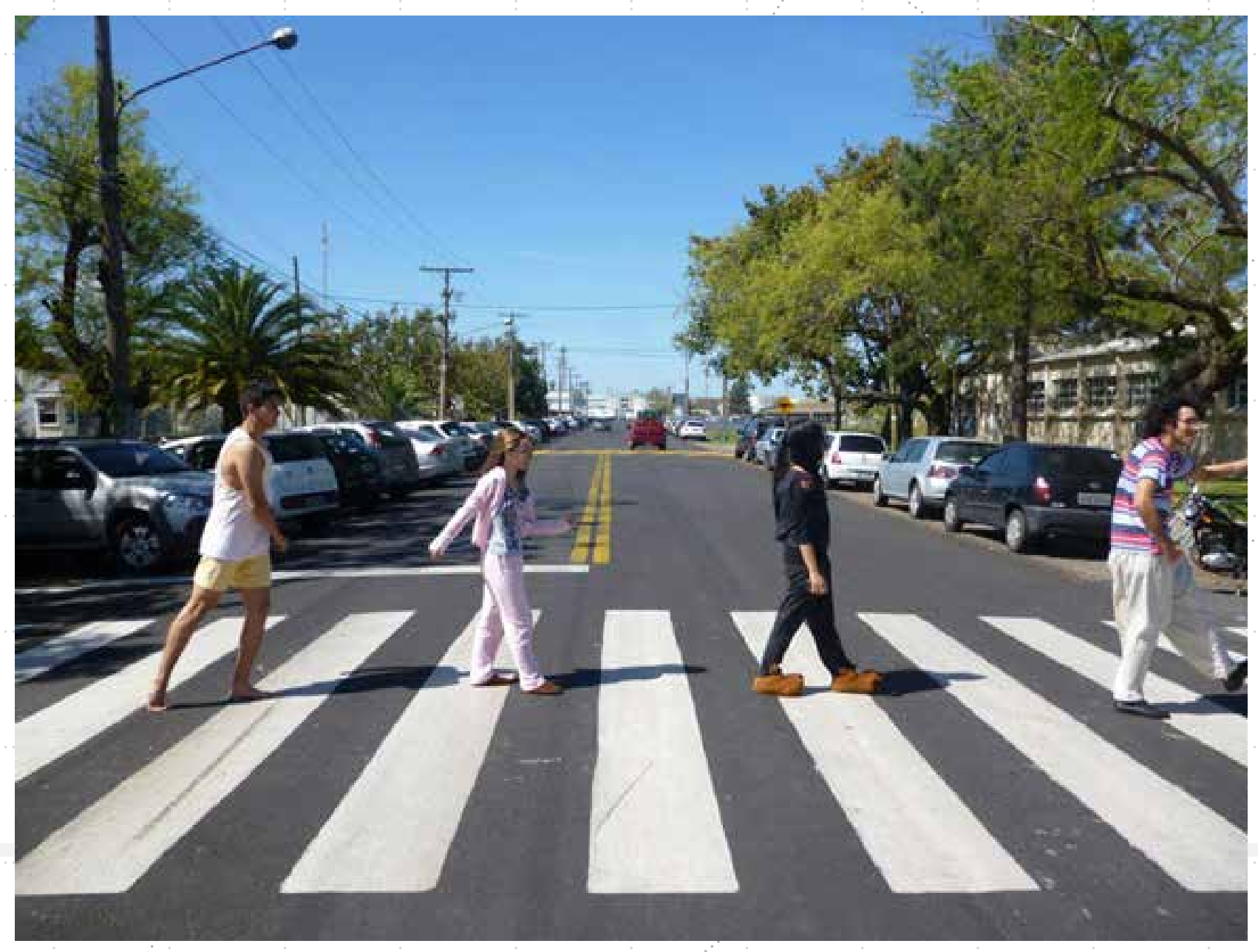

Figura 3. Releitura da capa do álbum Abbey Road lançado em 1969 pelos Beatles, ano 2012. Fotografia de Dandara Bueno Espíndola.
Ao romper com a concretude material do lugar cada jovem passou a tecer com sua rede de significados existenciais conceitos sínteses desse inicial ato de conhecer. E, assim, os alunos decidiram, sem combinação prévia, deixar o campus, estender as fronteiras da experiência e coletar respostas do público externo (Figuras 4 e 5). Os estudantes dirigiram-se ao centro comercial da cidade e após uma caminhada de 20 minutos finalizaram a atividade frente a Catedral de São Pedro - patrimônio histórico e artístico, por ser a primeira igreja erguida no estado do Rio Grande do Sul - onde uma ciranda em volta de suas mochilas finalizou a performance.

A atividade foi marcada por sua imprevisibilidade, um acontecimento cuja definição e, portanto, compreensão escapa aos que o testemunham ou que dele participam. Não é possível nomeá-lo, qualificá-lo. Não é possível prever ou conter a rota de aprendizagem estabelecida com a arte: na performance, na música, na igreja e na ciranda de roda.

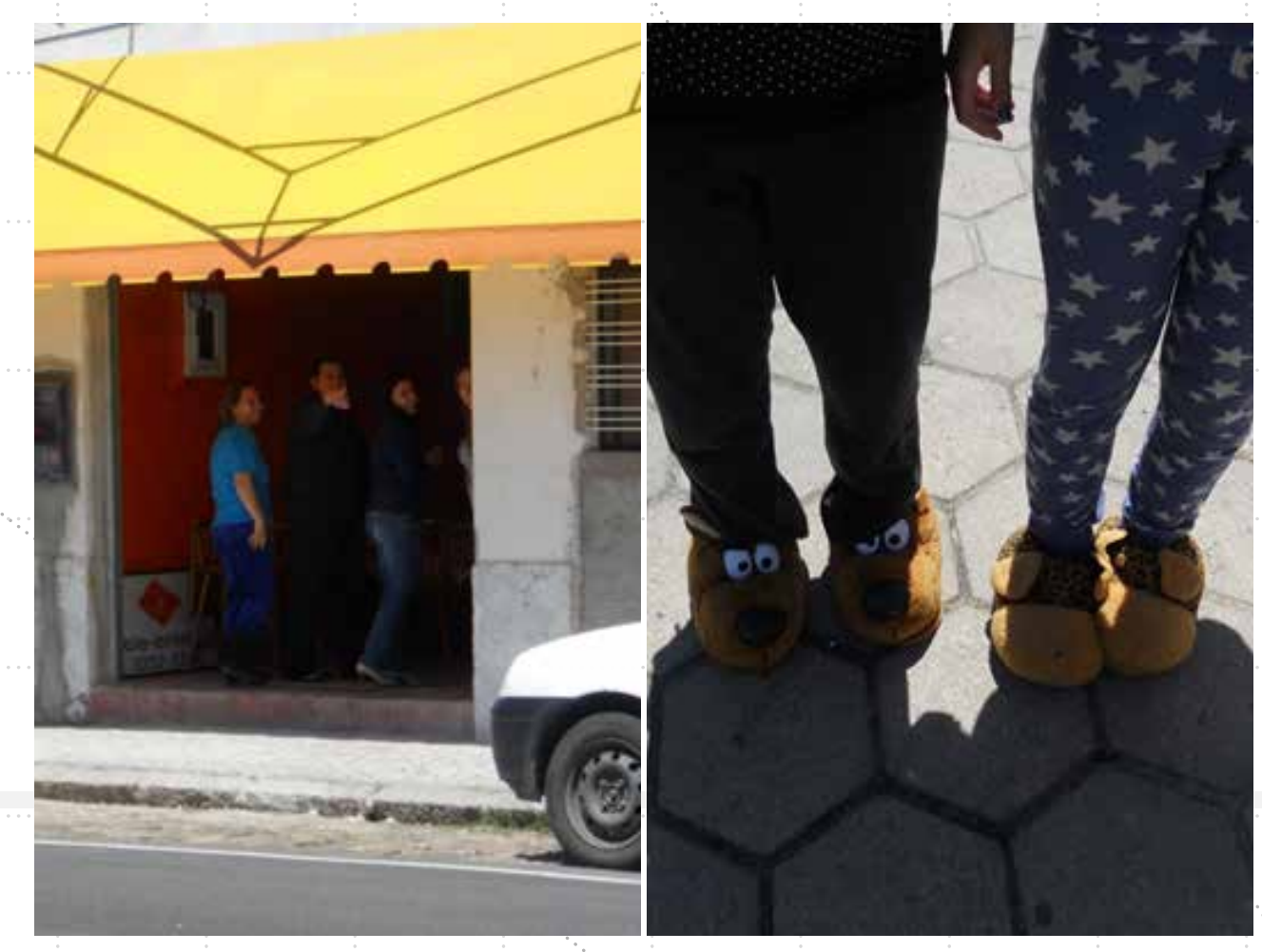

Figuras 4 e 5. Registro e reação durante o deslocamento do grupo fora do Campus, ano 2012. Fotografia de Dandara Bueno Espíndola. 
Para o público a atividade gerou surpresa, divertimento, espanto, dúvida, mas principalmente despertou o olhar da vida cotidiana. Uma vez cumprida a proposta os alunos viram-se apresentados a uma nova maneira de pensar a arte e experimentá-la, além de estabelecer relações com algumas moléstias que passam despercebidas no dia-a-dia. Ao ver-se pertencente a um grupo é possível enfrentar o escárnio sem maiores problemas, diferentemente do que acontece em casos de bullying, por exemplo.

Assim, a aprendizagem pode ser vista como um processo de expansão de dentro para fora; uma evolução do individual para o universal, seja na apreensão de conhecimento (reconhecer o conhecido) ou na produção de conhecimento (revelação do desconhecido). E o ato de conhecer ocorre através da verificação da manipulação conceitual, ou seja, o quanto a ideia original foi reinventada (reciclada) em nova contextualizaçẫo.

Acreditamos que quando o aluno olha o espaço e nele tem a possibilidade de traduzir seus desejos abre-se para um mundo de possibilidades, de tentativas e erros que muitas vezes se transformam em uma nova versão para sua história educativa. Assim, concordamos com Davydov, ano 1998 (apud LIBÂNEO, 2004, página 122). e Peralta (2012, página 58), para quem todo conceito científico é, simultaneamente, uma construção do pensamento e um reflexo do ser.

\section{REFERENCIAS BIBLIOGRÁFICAS}

BARBOSA Ana Mae (org.), Arte-educação: leituras no subsolo 7.ed São Paulo:Cortez, 2008.

Arte-educação no Brasil. 5 a.ed. São Paulo: Perspectiva, 2005.

BRASIL Ministério da Educação. PCN+: Orientações Educacionais Complementares aos Parâmetros Curriculares Nacionais - Linguagens, Códigos e suas Tecnologias -
Arte. Secretaria da Educação Básica. Brasília. MEC/SEB. Disponível em: http://portal. mec.gov.br/seb/arquivos/pdf/linguagens02.pdf

BRASIL. Ministério da Educação. Orientações Curriculares para o Ensino Médio: Linguagens, Códigos e suas Tecnologias - Arte. Secretaria da Educação Básica. Brasília. MEC/SEB, 2006. Disponível em: http://portal.mec.gov.br/seb/arquivos/pdf/ book_volume_01_internet.pdf

EISNER, Elliot. Estrutura e mágica no ensino da Arte. In: BARBOSA (org.), Arteeducação: leituras no subsolo. $7^{\text {a }}$.ed.São Paulo:Cortez, 2008.

FREIRE, Paulo. Educação como prática da liberdade. $14^{\text {aed. }}$. Rio de Janeiro: Paz e Terra, 1983.

KWECKO, Viviani Rios; GRACIA-TORCHELSEN, Liziane. Arte-educação-profissional: potencial de inventividade. Anais do XXII CONFAEB Arte/Educação: Corpos em Trânsito. Instituto de Artes / Universidade Estadual Paulista, 29 de outubro à 02 de novembro de 2012

LANIER, Vincent. Devolvendo arte à arte-educação. In: BARBOSA (org.), Arteeducação: leituras no subsolo. $7^{\text {a }}$.ed.São Paulo:Cortez, 2008.

LIBÃNEO, José Carlos. Aprendizagem escolar e a formação de professores na perspectiva da psicologia histórico-cultural e da teoria da atividade. Revista Educar, número 24, p. 113-147, Curitiba: Editora UFPR; 2004.

PERALTA-CASTELL, Cleusa Helena Guaita. Experimentos educacionais: eventos eurísticos transdisciplinares em educação ambiental. In: Ruscheinsky. Aloísio (org) Educação ambiontal - abordagens múltiplas. $2^{a}$. Edição. Porto Alegre: Penso, 2012

PRIBERAM Significado/definição de Flash Mob. Disponivel em: https://www. priberam.pt/dlpo/flashmob. Acessado em: 31 jan. 2017.

READ, H. Educação pela Arte. São Paulo: Martins Fontes, 2001.

VYGOTSKY Lev Semenivich. A construção do pensamento e da linguagem. São Paulo: Martins Fontes, 2001. (Psicologia e Pedagogia)
DARALELӨ3I ediçao 07: dezembro de 2016

Viviani Rios. Kwecko; Dandara Bueno Espíndola i 